Supplement of Biogeosciences, 18, 4369-4388, 2021 https://doi.org/10.5194/bg-18-4369-2021-supplement (c) Author(s) 2021. CC BY 4.0 License.

(c) (1)

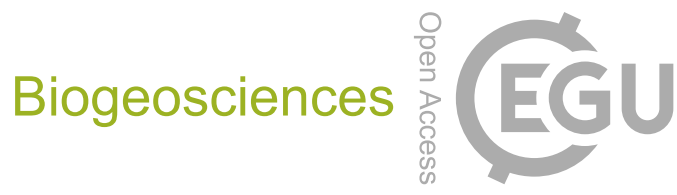

Supplement of

\title{
Carbon sources of benthic fauna in temperate lakes across multiple trophic states
}

\section{Annika Fiskal et al.}

Correspondence to: Annika Fiskal (annikafiskal@gmail.com) and Mark A. Lever (mark.lever@usys.ethz.ch)

The copyright of individual parts of the supplement might differ from the article licence. 


\section{Supplementary Information}

Table S1: qPCR primers and standards and their corresponding references

\begin{tabular}{|c|c|c|c|c|}
\hline Target & Primer & Sequence 5' - 3' & Reference & Standard \\
\hline Archaeal & Arc915F_mod & AAT TGG CGG GGG AGC AC & Cadillo-Quiroz et al. (2006) & \multirow{2}{*}{$\begin{array}{l}\text { Thermoplasma } \\
\text { acidophilum }\end{array}$} \\
\hline $16 S$ rRNA & $\overline{A r c 1059 R}$ & GCC ATG CAC CWC CTC T & Yu et al. (2005) & \\
\hline Bacterial & Bac908F_mod & AAC TCA AAK GAA TTG ACG GG & Lever et al. (2015) & \multirow{2}{*}{$\begin{array}{l}\text { Desolfotignum } \\
\text { phosphitoxidans }\end{array}$} \\
\hline $16 S$ rRNA & Bac1075R & CAC GAG CTG ACG ACA RCC & Ohkuma and Kudo (1998) & \\
\hline \multirow[t]{2}{*}{$\overline{p m o A}$} & A189F & GGN GAC TGG GAC TTC TGG & Holmes et al. (1995) & \multirow{2}{*}{$\begin{array}{l}\text { Methylococcus } \\
\text { capsulatus }\end{array}$} \\
\hline & $\overline{M b 661 R}$ & CCG GMG CAA CGT CYT TAC C & Costello and Lidstrom (1999) & \\
\hline \multirow[t]{2}{*}{$m c r A$} & Mlas_F & GGT GGT GTM GGD TTC ACM CAR TA & Steinberg and Regan (2009) & \multirow{2}{*}{$\begin{array}{l}\text { Methanocorpusculum } \\
\text { parvum }\end{array}$} \\
\hline & mcrA-rev & CGT TCA TBG CGT AGT TVG GRT AGT & Steinberg and Regan (2009) & \\
\hline
\end{tabular}

Table S2: qPCR protocols for each primer pair.

\begin{tabular}{|c|c|c|c|}
\hline Primer target: & & Arc & pmoA merA \\
\hline qPCR step & time (min:s) & \multicolumn{2}{|c|}{ primer-specific temperature $\left({ }^{\circ} \mathrm{C}\right)$} \\
\hline 1. Initial Activation & 05:00 & \multicolumn{2}{|l|}{ Always 95} \\
\hline 2. Denaturation & $00: 10$ & \multicolumn{2}{|l|}{ Always 95} \\
\hline 3. Annealing & $00: 30$ & 60 & (62) $52 \quad 56$ \\
\hline 4. Polymerization & $00: 15$ & \multicolumn{2}{|l|}{ Always 72} \\
\hline 5. Acquisition & $00: 05$ & 82 & 80 \\
\hline \multicolumn{2}{|c|}{ Cycle repeats step 2.-5. } & 40 & $(10+) 3540$ \\
\hline 6. Denaturation & $01: 15$ & \multicolumn{2}{|l|}{ Always 95} \\
\hline 7. Acquisition & continuous & $55-95$ & $60-95$ \\
\hline 8. Cooling & $\infty$ & \multicolumn{2}{|l|}{ Always 4} \\
\hline
\end{tabular}

5

Table S3: Overview of chemicals used in the different master mix for PCR for one reaction ( $25 \mu$ lotal reaction volume) (A). Temperate and time protocols used for each PCR during library preparation. Underlined are the steps which are repeated (cycle number), see main text for details (B).

(A)

\begin{tabular}{|c|c|c|c|}
\hline & Boost PCR & Tail PCR & Index PCR \\
\hline Go Taq G2 DNA Polymerase $(5 \mu \mathrm{l} / \mathrm{ml})$ & $0.125 \mu \mathrm{l}$ & $0.125 \mu 1$ & $0.125 \mu \mathrm{l}$ \\
\hline Go Taq Colorless reaction buffer $(5 x)$ & $5 \mu \mathrm{l}$ & $5 \mu \mathrm{l}$ & $5 \mu \mathrm{l}$ \\
\hline PCR nucleotide mix $(10 \mathrm{mM})$ & $0.5 \mu 1$ & $0.5 \mu 1$ & $0.5 \mu 1$ \\
\hline primer 1 & $0.75 \mu \mathrm{l}$ & $0.75 \mu \mathrm{l}(0.1875$ of each: nex0-nex3) & $2.5 \mu 1$ \\
\hline primer 2 & $0.75 \mu 1$ & $0.75 \mu \mathrm{l}(0.1875$ of each: nex0-nex3) & $2.5 \mu 1$ \\
\hline BSA & $1.25 \mu 1$ & none & none \\
\hline $\mathrm{H}_{2} \mathrm{O}$ (mol. grade) & $14.625 \mu 1$ & $16.875 \mu 1$ & $12.375 \mu 1$ \\
\hline Template & $2 \mu 1$ & $1 \mu 1$ & $2 \mu 1$ \\
\hline
\end{tabular}

(B)

\begin{tabular}{llll}
\hline & \multicolumn{4}{l}{ Temperature $\left({ }^{\circ} \mathbf{C}\right) /$ Time $($ min:s) } \\
\hline PCR & Boost & Tail & Index \\
\hline Activation & $95 / 05: 00$ & $95 / 02: 00$ & $95 / 02: 00$ \\
\hline Denaturation & $98 / 00: 20$ & $95 / 00: 20$ & $95 / 00: 20$ \\
\hline Annealing & $49 / 00: 30$ & $49 / 00: 30$ & $55 / 00: 40$ \\
\hline Polymerization & $72 / 00: 30$ & $72 / 00: 30$ & $72 / 00: 30$ \\
\hline Denaturation & $72 / 05: 00$ & $72 / 05: 00$ & $72 / 05: 00$ \\
\hline Cooling & $4 / \infty$ & $4 / \infty$ & $4 / \infty$ \\
\hline
\end{tabular}


Table S4: ${ }^{13} \mathrm{C}-\mathrm{C}$ of specific sediment layers and phytoplankton samples from this study (A) and literature (B). For plankton samples, 'surface' indicates surface water samples that were obtained using plankton tows with different mesh sizes. Asterisks indicate samples that were not decarbonized.

(A)
\begin{tabular}{|l|l|l|l|l|l|}
\hline Lake & Station & Type & depth & size or feature & $\boldsymbol{\delta}^{\mathbf{1 3}}$ C \\
\hline Lucerne & shore & phytoplankton & surface & $>50 \mu \mathrm{m}$ & $-26.3^{*}$ \\
\hline Lucerne & shore & phytoplankton & surface & $>100 \mu \mathrm{m}$ & $-29.4^{*}$ \\
\hline Lucerne & shore & phytoplankton & surface & $>20 \mu \mathrm{m}$ & -30.1 \\
\hline Lucerne & shore & phytoplankton & surface & $>20 \mu \mathrm{m}$ & $-19.5^{*}$ \\
\hline Lucerne & shore & phytoplankton & surface & $>20 \mu \mathrm{m}$ & -31.2 \\
\hline Lucerne & shore & phytoplankton & surface & $>20 \mu \mathrm{m}$ & $-26.7^{*}$ \\
\hline Lucerne & shore & phytoplankton & surface & $20-100 \mu \mathrm{m}$ & $-29.5^{*}$ \\
\hline Lucerne & shore & phytoplankton & surface & $>50 \mu \mathrm{m}$ & -30.3 \\
\hline Lucerne & shore & phytoplankton & surface & $>50 \mu \mathrm{m}$ & $-21.1^{*}$ \\
\hline Baldegg & 1 & sediment & $21 \mathrm{~cm}$ & layer & -35.4 \\
\hline Zurich & 1 & sediment & $2-2.5 \mathrm{~cm}$ & algal bloom & -33.7 \\
\hline Greifen & 1 & sediment & 13 & layer & -34.1 \\
\hline Zurich & 3 & sediment & $18.5 \mathrm{~cm}$ & sediment with plant material & -29.1 \\
\hline Zurich & 3 & sediment & $18.5 \mathrm{~cm}$ & plant material (leaves, wood) & -29.2 \\
\hline Greifen & 3 & sediment & $14-15 \mathrm{~cm}$ & layer & -35.7 \\
\hline Baldegg & 1 & sediment & $21 \mathrm{~cm}$ & brighter layer & -35.6 \\
\hline
\end{tabular}

(B)

\begin{tabular}{|l|l|l|l|}
\hline Target & $\boldsymbol{\delta}^{\mathbf{1 3}}$ C range (\%) & Environment & Reference \\
\hline Phytoplankton & -34.4 to -5.9 & sub-arctic lakes & Vuorio et al. $(2006)$ \\
\hline Phytoplankton & -36.6 to -28.7 & Lake Memphremagog, Quebec & Lazerte (1983) \\
\hline Algae & -35 to -15 & small water bodies Australia & Boon and Bunn (1994) \\
\hline Floating plants & -32 to -25 & & \\
\hline Emergent macrophytes & -31 to -25 & & \\
\hline Submerged macrophytes & -33 to -15 & & \\
\hline Epiphytes & -32 to -20 & & \\
\hline Freshwater seston & -35.2 to -23.9 & Sacramento-San Joaquin River Delta & Cloern et al. $(2002)$ \\
\hline sediment trap OM & -40 to -22 & Lake Lugano & Bernasconi et al. $(1997)$ \\
\hline sediment trap POC & -39 to -27 & Lake Greifen (yearly cycle) & Hollander et al. (1993) \\
\hline POC & -60 to -20 & Lake Lugano (yearly cycle) & Lehmann et al. $(2004)$ \\
\hline
\end{tabular}

Table S5: Abundance of Oligochaetes and Chironomid Larvae per $\mathbf{m}^{2}$ for each Lake station, indicated are averages of the three stations and the corresponding standard deviations (SD), please note for Lake Zurich averages and SD were calculated from station

2 and 3 only (*).

\begin{tabular}{ccc}
\hline Lake & Oligochaetes $\left(\mathbf{m}^{-\mathbf{2}}\right)$ & Chironomid Larvae $\left.\mathbf{( m}^{\mathbf{- 2}}\right)$ \\
\hline Lucerne & & \\
Station 1 & 170 & 1019 \\
Station 2 & 57 & 340 \\
Station 3 & 0 & 566 \\
Average $( \pm S D)$ & $75( \pm 86)$ & $641( \pm 346)$ \\
\hline Zurich & 0 & 0 \\
Station 1 & 906 & 962 \\
Station 2 & 1302 & 736 \\
Station 3 & $1104( \pm 280)$ & $849( \pm 160)$ \\
Average $( \pm S D) *$ & 1132 & 57 \\
\hline Zug & 1245 & 0 \\
Station 1 & 1641 & 57 \\
Station 2 & $1340( \pm 267)$ & $38( \pm 33)$ \\
Station 3 & & \\
Average $( \pm S D)$ & 3339 & 0 \\
\hline Greifen & 962 & 0 \\
Station 1 & 3736 & 0 \\
Station 2 & $2679( \pm 1500)$ & - \\
Station 3 & & 57 \\
Average $( \pm S D)$ & 9282 & 0 \\
\hline Baldegg & 4868 & 170 \\
Station 1 & 396 & $75( \pm 86)$ \\
Station 2 & $4849( \pm 4443)$ & \\
Station 3 & & \\
Average $( \pm S D)$ & &
\end{tabular}


Table S6: (A): food sources and feeding modes as well as distributions of oligochaete worms, and (B): of chironomid larvae, where feeding modes are after Moog (2002).

(A)

\begin{tabular}{|c|c|c|c|}
\hline Taxa & Food source and feeding mode & Distribution & Reference \\
\hline $\begin{array}{l}\text { Embolocephalus } \\
\text { velutinus }\end{array}$ & $\begin{array}{l}\text { Naididae: look for food at surface of } \\
\text { sediment or other surfaces, most surface } \\
\text { deposit feeders }\end{array}$ & $\begin{array}{l}\text { oligo- und mesotrophic lakes, cold } \\
\text { stenothermic species }\end{array}$ & \multirow{6}{*}{$\begin{array}{l}\text { Van Haaren and Soors } \\
\text { (2013); (Martin et al. } \\
\text { (2008); } \\
\text { Brinkhurst (1982) } \\
\text { Brinkhurst and Chua } \\
\text { (1969) }\end{array}$} \\
\hline $\begin{array}{l}\text { Limnodrilus } \\
\text { hoffmeisteri }\end{array}$ & \multirow[t]{5}{*}{$\begin{array}{l}\text { all Tubificidae are thought to be subsurface } \\
\text { deposit feeders that take in sediment: and } \\
\text { mainly feed on bacteria (and algae) as } \\
\text { main food source }\end{array}$} & $\begin{array}{l}\text { in eu- to hypereutrophic lakes, very } \\
\text { tolerant to oxygen deficiencies, } \\
\text { omnipresent, wide ecological valence }\end{array}$ & \\
\hline $\begin{array}{l}\text { Limnodrilus } \\
\text { profundicola }\end{array}$ & & & \\
\hline $\begin{array}{l}\text { Potamothrix } \\
\text { hammoniensis }\end{array}$ & & $\begin{array}{l}\text { Mostly in bigger lakes, correlates with } \\
\text { organic part in sediment originating } \\
\text { from algae, omnipresent species with } \\
\text { wide ecological valence }\end{array}$ & \\
\hline $\begin{array}{l}\text { Potamothrix } \\
\text { veydovskyi }\end{array}$ & & $\begin{array}{l}\text { indicative for mid to high pollution, } \\
\text { eutrophic conditions }\end{array}$ & \\
\hline Tubifex tubifex & & $\begin{array}{l}\text { Widespread. Often dominant under } \\
\text { eutrophic or highly oligotrophic } \\
\text { conditions. }\end{array}$ & \\
\hline
\end{tabular}




\begin{tabular}{|c|c|c|c|}
\hline Taxa & Food sources and feeding mode & Distribution & Reference \\
\hline Sergentia coracina & $\begin{array}{l}\text { mainly detritus feeder (gathering collector), } \\
\text { also filter feeding of sedimented fine } \\
\text { particulate OM. } \\
\text { Stretch out of tubes and feed from surrounding } \\
\text { mud, mud dwellers. }\end{array}$ & & Pillot (2009) \\
\hline $\begin{array}{l}\text { Paracladopelma } \\
\text { laminatum }\end{array}$ & mainly predators & \multicolumn{2}{|c|}{$\begin{array}{l}\text { Less } \mathrm{Fe}(\mathrm{II}) \text { tolerant }<0.2 \mathrm{mg} \mathrm{Fe}(\mathrm{II}) / \mathrm{L} \text {, eutrophic Pillot }(2009) \\
\text { lakes, rarely in oligotrophic lakes, tolerant of } \\
\text { organic loading }\end{array}$} \\
\hline Procladius sp. & \multirow{2}{*}{\multicolumn{3}{|c|}{\begin{tabular}{|l|l|l|}
$\begin{array}{l}\text { mainly predators, also detritus feeding of algae in mineral and organic sediment, stagnant and } \\
\text { (gathering collector), prey are small slow flow water types, warm water chironomid, } \\
\text { crustaceans and later in life cycle chironomidae lower critical } \mathrm{O}_{2} \text { concentration } \\
\text { and oligochaetes. }\end{array}$ & $\begin{array}{l}\text { Pallot } \\
\text { Brodersen et al. }\end{array}$ \\
$\begin{array}{l}\text { mainly detritus feeders (gathering collector), } \\
\text { also grazing (scrapers, raspers) and filter } \\
\text { feeding of sedimented fine particulate OM, } \\
\text { build tubes }\end{array}$ & \\
\end{tabular}}} \\
\hline $\begin{array}{l}\text { Tanytarsus } \\
\text { norvegicus }\end{array}$ & & & \\
\hline $\begin{array}{l}\text { Macropelopia } \\
\text { fehlmanni }\end{array}$ & $\begin{array}{l}\text { mainly predacious, also detritus feeding, prey } \\
\text { are mainly chironomidae, plecoptera, } \\
\text { copeopoda, detritus }\end{array}$ & & 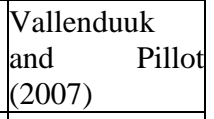 \\
\hline $\begin{array}{l}\text { Chironomus } \\
\text { riparius/piger gr. }\end{array}$ & \multicolumn{3}{|c|}{$\begin{array}{l}\text { mainly filter feeder, also shredders and grazers, } 4-7 \text { generations a year, emerging from march to Pillot (2009) } \\
\text { of suspended FPOM, CPOM, fallen leaves, november, one generation } 34.8 \text { days at } 15{ }^{\circ} \mathrm{C}, \text { Stief et al. } \\
\text { plant tissue, terrestrial and algal OMprefer organic muddy substrate with }(2005) \\
\text { (Goedkoop et al. 2006), but believed to switch characteristic for polluted flowing water, heavy Goedkoop et al. } \\
\text { from mainly surface deposit-feeding toload of OM, warm water chironomid, lower( } 2006) \\
\text { microbial gardening under hypoxic conditions critical } \mathrm{O}_{2} \text { concentrations } \\
\text { (Stief et al. 2005) } \\
\text { Brodersen et al. } \\
\text { (2004) }\end{array}$} \\
\hline Ablabesmyia monilis & $\begin{array}{l}\text { mainly predators, also detritus feeding, actively } \\
\text { attacking chironomidae, oligochaetes and } \\
\text { partially cladocera but also dead prey (diatoms, } \\
\text { detritus) }\end{array}$ & $\begin{array}{l}\text { warm water chironomid, lower critical } \mathrm{O}_{2} \\
\text { concentrations }\end{array}$ & $\begin{array}{l}\text { Vallenduuk } \\
\text { and } \\
(2007)\end{array}$ \\
\hline Tanytarsus sp. & $\begin{array}{l}\text { mainly detritus feeding, but also grazing and } \\
\text { filter feeding of sedimented fine particulate } \\
\text { OM, build tubes }\end{array}$ & oligo to mesotrophic lakes (Saether, 1980) & $\begin{array}{l}\text { Wotton (1996) } \\
\text { Brodersen et al. } \\
(2004)\end{array}$ \\
\hline Micropsectra sp. & $\begin{array}{l}\text { mainly detritus feeding, but also grazing and } \\
\text { filter feeding of sedimented fine particulate } \\
\text { OM }\end{array}$ & & Saether (1980) \\
\hline Stempellina bausei & $\begin{array}{l}\text { grazing and detritus feeding, of epilithic algal } \\
\text { tissue, biofilm, partially POM (endo and } \\
\text { epilithic algal tissue, partially living plant } \\
\text { tissue) }\end{array}$ & & \\
\hline $\begin{array}{l}\text { Orthocladiinae gen. } \\
\text { sp. }\end{array}$ & mainly algae & & $\begin{array}{l}\text { Stevenson et al. } \\
(1996)\end{array}$ \\
\hline $\begin{array}{l}\text { Polypedilum } \\
\text { nubeculosum }\end{array}$ & $\begin{array}{l}\text { mainly detritus feeding, but also grazing and } \\
\text { filter feeding of sedimented fine particulate } \\
\text { OM, Bacteria seem to be most important food } \\
\text { (Moore, 1979) }\end{array}$ & $\begin{array}{l}\text { 2-3 generations adults emerge from the end of } \\
\text { April to early October when temp in spring } \\
\text { reaches } 8^{\circ} \mathrm{C} \text {, bottom dwellers, make long tubes, } \\
\text { density correlated with oxygen contents, organic } \\
\text { sediment }\end{array}$ & \\
\hline Chironomus sp. & $\begin{array}{l}\text { mainly filter feeding, also shredders and } \\
\text { grazers of suspended FPOM, CPOM, prey, } \\
\text { build tubes }\end{array}$ & & \\
\hline $\begin{array}{l}\text { Chironomus } \\
\text { commutatus }\end{array}$ & $\begin{array}{l}\text { mainly filter feeding, also shredders and } \\
\text { grazers of suspended FPOM, CPOM, prey, } \\
\text { build tubes }\end{array}$ & & Pillot (2009) \\
\hline
\end{tabular}


Table S7: Depth distribution of oligochaete (A) and chironomid (B) species in each lake

\section{A: Oligochaetes}

\begin{tabular}{|c|c|c|c|c|c|c|}
\hline Lake & \multicolumn{5}{|c|}{ \# of individuals per species } & \multirow{2}{*}{$\begin{array}{l}\text { Total \# of } \\
\text { individuals }\end{array}$} \\
\hline $\begin{array}{l}\text { Depth } \\
\text { (cm) }\end{array}$ & $\begin{array}{l}\text { Tubificidae } \\
\text { (+bristles) }\end{array}$ & $\begin{array}{l}\text { Tubificidae (- } \\
\text { bristles) }\end{array}$ & $\begin{array}{l}\text { Tubifex } \\
\text { Tubifex }\end{array}$ & $\begin{array}{l}\text { Limnodrilus } \\
\text { hoffmeisteri }\end{array}$ & $\begin{array}{l}\text { Limnodrilus } \\
\text { profundicula }\end{array}$ & \\
\hline $0-1$ & & 2 & & 1 & & 3 \\
\hline $1-2$ & & 5 & & & & 5 \\
\hline $2-3$ & & & & & & \\
\hline $3-4$ & & & & & & \\
\hline $4-6$ & 1 & 9 & & 11 & 10 & 31 \\
\hline $6-8$ & 2 & 19 & 1 & 26 & 4 & 52 \\
\hline $8-10$ & & & & & & \\
\hline $10-12$ & & 15 & & 11 & & 26 \\
\hline
\end{tabular}

\begin{tabular}{|c|c|c|c|c|c|c|}
\hline \multirow{2}{*}{$\begin{array}{l}\text { Lake } \\
\text { Greifen } \\
\text { Depth } \\
(\mathrm{cm})\end{array}$} & \multicolumn{5}{|c|}{ \# of individuals per species } & \multirow{2}{*}{$\begin{array}{l}\text { Total \# of } \\
\text { individuals }\end{array}$} \\
\hline & $\begin{array}{l}\text { Tubificidae } \\
\text { (+bristles) }\end{array}$ & $\begin{array}{l}\text { Tubificidae ( } \\
\text { bristles) }\end{array}$ & $\begin{array}{l}\text { Tubifex } \\
\text { Tubifex }\end{array}$ & $\begin{array}{l}\text { Limnodrilus } \\
\text { hoffmeisteri }\end{array}$ & $\begin{array}{l}\text { Potamothrix } \\
\text { hammoniensis }\end{array}$ & \\
\hline \multicolumn{7}{|l|}{$0-1$} \\
\hline $1-2$ & 6 & & & & & 6 \\
\hline $2-3$ & 10 & 1 & & & 4 & 15 \\
\hline $3-4$ & 5 & & & & & 5 \\
\hline $4-6$ & 8 & & 1 & & 4 & 13 \\
\hline $6-8$ & 10 & & 2 & 1 & & 13 \\
\hline $8-10$ & 3 & & 2 & & & 5 \\
\hline $10-12$ & & & & & & \\
\hline
\end{tabular}

\begin{tabular}{|c|c|l|l|l|l|c|}
\hline Lake Zug & \multicolumn{4}{|l|}{ \# of individuals per species } & $\begin{array}{l}\text { Total \# of } \\
\text { individuals }\end{array}$ \\
\hline $\begin{array}{c}\text { Depth } \\
\text { (cm) }\end{array}$ & $\begin{array}{l}\text { Tubificidae } \\
\text { (+bristles) }\end{array}$ & $\begin{array}{l}\text { Tubificidae (- } \\
\text { bristles) }\end{array}$ & $\begin{array}{l}\text { Tubifex } \\
\text { Tubifex }\end{array}$ & $\begin{array}{l}\text { Limnodrilus } \\
\text { hoffmeisteri }\end{array}$ & $\begin{array}{l}\text { Potamothrix } \\
\text { hammoniensis }\end{array}$ & \\
\hline $0-1$ & & & & & & \\
\hline $1-2$ & 4 & & & & & $\mathbf{4}$ \\
\hline $2-3$ & & 3 & & & & $\mathbf{3}$ \\
\hline $3-4$ & & & & & & \\
\hline $4-6$ & 2 & 2 & 2 & & & $\mathbf{1 0}$ \\
\hline $6-8$ & & & & & & \\
\hline $8-10$ & 3 & 1 & 1 & & & $\mathbf{5}$ \\
\hline $10-12$ & 3 & & 2 & & & $\mathbf{5}$ \\
\hline $12-14$ & & & & & & \\
\hline $14-16$ & 2 & & & & & $\mathbf{2}$ \\
\hline $16-18$ & & & & & & \\
\hline
\end{tabular}




\begin{tabular}{|c|c|c|c|c|c|c|}
\hline \multirow{2}{*}{$\begin{array}{l}\text { Lake } \\
\text { Zurich } \\
\text { Depth } \\
\text { (cm) }\end{array}$} & \multicolumn{5}{|c|}{ \# of individuals per species } & \multirow{2}{*}{$\begin{array}{l}\text { Total \# of } \\
\text { individuals }\end{array}$} \\
\hline & $\begin{array}{l}\text { Tubificidae } \\
\text { (+bristles) }\end{array}$ & $\begin{array}{l}\text { Tubificidae (- } \\
\text { bristles) }\end{array}$ & $\begin{array}{l}\text { Embolocephalus } \\
\text { velutinus }\end{array}$ & $\begin{array}{l}\text { Limnodrilus } \\
\text { hoffmeisteri }\end{array}$ & $\begin{array}{l}\text { Potamothrix } \\
\text { hammoniensis }\end{array}$ & \\
\hline \multicolumn{7}{|l|}{$0-1$} \\
\hline \multicolumn{7}{|l|}{$1-2$} \\
\hline $2-3$ & 1 & & & & & 1 \\
\hline $3-4$ & 5 & & & & 1 & 6 \\
\hline $4-6$ & 1 & & 1 & 1 & 2 & 5 \\
\hline $6-8$ & 3 & 1 & & & 1 & 5 \\
\hline \multicolumn{7}{|l|}{$8-10$} \\
\hline $10-12$ & & 1 & & & & 1 \\
\hline
\end{tabular}

\begin{tabular}{|c|c|c|}
\hline $\begin{array}{l}\text { Lake } \\
\text { Lucerne }\end{array}$ & \# of individuals per species & $\begin{array}{c}\text { Total \# of } \\
\text { individuals }\end{array}$ \\
\hline $\begin{array}{l}\text { Depth } \\
\text { (cm) }\end{array}$ & Potamothrix vejdoyski & \\
\hline $0-1$ & & \\
\hline $1-2$ & 1 & $\mathbf{1}$ \\
\hline $2-3$ & & \\
\hline $3-4$ & & \\
\hline $4-6$ & & \\
\hline $6-8$ & & \\
\hline $8-10$ & & \\
\hline $10-12$ & & \\
\hline
\end{tabular}

\section{B: Larvae}

\begin{tabular}{|c|l|l|l|c|}
\hline $\begin{array}{l}\text { Lake } \\
\text { Baldegg }\end{array}$ & \multicolumn{2}{|l|}{ \# of individuals per species } & $\begin{array}{c}\text { Total \# of } \\
\text { individuals }\end{array}$ \\
\hline $\begin{array}{l}\text { Depth } \\
\text { (cm) }\end{array}$ & $\begin{array}{l}\text { Micropsectra } \\
\text { sp. }\end{array}$ & $\begin{array}{l}\text { Chironomus } \\
\text { riparius/piger gr. }\end{array}$ & $\begin{array}{l}\text { Orthocladiinae } \\
\text { gen. Sp. }\end{array}$ & \\
\hline $0-1$ & & & & 1 \\
\hline $1-2$ & 1 & & & 1 \\
\hline $2-3$ & & & & 1 \\
\hline $3-4$ & & & & \\
\hline $4-6$ & & & & \\
\hline $6-8$ & & & & \\
\hline $8-10$ & & & & \\
\hline $10-12$ & & & & \\
\hline $12-14$ & & & & \\
\hline $14-16$ & & & & \\
\hline $16-18$ & & & & \\
\hline
\end{tabular}

5

\begin{tabular}{|c|l|l|c|}
\hline Lake Zug & \multicolumn{2}{|l|}{ \# of individuals per species } & $\begin{array}{c}\text { Total \# of } \\
\text { individuals }\end{array}$ \\
\hline $\begin{array}{l}\text { Depth } \\
\text { (cm) }\end{array}$ & $\begin{array}{l}\text { Sergentia } \\
\text { coracina }\end{array}$ & Procladius sp. & \\
\hline $0-1$ & & & 1 \\
\hline $1-2$ & 1 & & 1 \\
\hline $2-3$ & & & $\mathbf{1}$ \\
\hline $3-4$ & & 1 & \\
\hline
\end{tabular}




\begin{tabular}{|c|c|c|c|c|c|c|c|c|c|c|}
\hline \multirow{2}{*}{$\begin{array}{l}\text { Lake } \\
\text { Zurich } \\
\text { Depth } \\
\text { (cm) }\end{array}$} & \multicolumn{9}{|c|}{ \# of individuals per species * } & \multirow{2}{*}{$\begin{array}{r}\text { Total \# of } \\
\text { individuals }\end{array}$} \\
\hline & $\begin{array}{l}\text { S. cora- } \\
\text { cina }\end{array}$ & $\begin{array}{l}\text { P. } \\
\text { sp. }\end{array}$ & $\begin{array}{l}\text { T. norve- } \\
\text { gicus }\end{array}$ & $\begin{array}{l}\text { C. riparius } \\
\text { /piger gr. }\end{array}$ & $\begin{array}{l}\text { T. } \\
\text { sp. }\end{array}$ & M. sp. & $\begin{array}{l}\text { P. nube- } \\
\text { culosum }\end{array}$ & $\begin{array}{l}\text { C. } \\
\text { sp. }\end{array}$ & $\begin{array}{l}\text { C. } \\
\text { commutatus }\end{array}$ & \\
\hline $0-1$ & 1 & & & & & 2 & & & & 3 \\
\hline $1-2$ & & & & & 1 & 2 & & & & 3 \\
\hline $2-3$ & 1 & & 1 & 2 & & 2 & 1 & & & 7 \\
\hline \multicolumn{11}{|l|}{$3-4$} \\
\hline $4-6$ & 1 & & & 1 & & & & & & 2 \\
\hline $6-8$ & 1 & 1 & & 2 & & & & & & 4 \\
\hline $8-10$ & & & & & & & & & 2 & 2 \\
\hline $10-12$ & & & & & & 1 & & 1 & & 2 \\
\hline $12-14$ & & & & & & & & 1 & & 1 \\
\hline $14-16$ & & & & & 2 & & & & & 2 \\
\hline $16-18$ & & & & & 1 & & & & & 1 \\
\hline \multicolumn{11}{|l|}{$18-20$} \\
\hline $20-24$ & & & & & 1 & 1 & & & & 2 \\
\hline
\end{tabular}

\begin{tabular}{|c|c|c|c|c|c|c|c|c|c|c|c|}
\hline Lake & \# of in & iduals pe & species * & & & & & & & & Total \# of \\
\hline $\begin{array}{l}\text { Depth } \\
\text { (cm) }\end{array}$ & $\begin{array}{l}\text { S. } \\
\text { cora- } \\
\text { cina }\end{array}$ & $\begin{array}{l}\text { P. lami- } \\
\text { natum }\end{array}$ & $\begin{array}{l}\text { T. } \\
\text { norve- } \\
\text { gicus }\end{array}$ & $\begin{array}{l}\text { C. riparius } \\
\text { /piger gr. }\end{array}$ & $\begin{array}{l}\text { T. } \\
\text { sp. }\end{array}$ & $\begin{array}{l}\text { M. } \\
\text { sp. }\end{array}$ & $\begin{array}{l}\text { A. } \\
\text { monilis }\end{array}$ & $\begin{array}{l}\text { P. } \\
\text { sp. }\end{array}$ & $\begin{array}{l}\text { M. } \\
\text { fehl- } \\
\text { manni }\end{array}$ & $\begin{array}{l}\text { S. } \\
\text { bausei }\end{array}$ & \\
\hline $0-1$ & 1 & & & & 3 & & 1 & & & & 5 \\
\hline $1-2$ & 1 & 1 & 2 & & & 5 & & 3 & 2 & & 14 \\
\hline $2-3$ & 1 & & & & & & & 1 & & & 2 \\
\hline $3-4$ & & & & & & & & 2 & 1 & 1 & 4 \\
\hline $4-6$ & & & & & & & & 5 & & & 5 \\
\hline $6-8$ & & & & 1 & & & & & & & 1 \\
\hline
\end{tabular}

$*$ S. coracina $=$ Sergentia coracina, $P$.laminatum $=$ Paracladopelma laminatum, $T$. novergicus $=$ Tanytarsus norvegicus, $T$. sp. $=$ Tanytarsus sp., M. sp. = Micropsectra sp., A. monilis = Ablabesmyia monilis, $P . s p .=$ Procladius $s p .$, , fehlmanni = Macropelopia fehlmanni, $S$. bausei $=$ Stempellina bausei, $C . x x x x x=$ Chironomus xxxxx, $P$. nubeculosum $=$ Polypedilum nubeculosum. 
Table S8: Overview of ZOTUs that were enriched (>5\% of total reads) or highly enriched ( $>50 \%$ of total reads) in whole macrofaunal specimen (w), macrofaunal guts (g), or macrofaunal bodies after gut removal (b). Oligochaetes are shown in (A), chironomid larvae in (B). Classifications were done to the genus- or family-level via phylogenetic trees with manually optimized alignments in the ARB software (Ludwig et al. (2004), Supplementary Fig. S8). Fractions indicate the number of w, b, or $\mathrm{g}$ analyzed per lake in which a 5 ZOTU was enriched (second column from right) or highly enriched (right column). LB = Lake Baldegg, LG = Lake Greifen, LZug = Lake Zug, $\mathbf{L Z}=$ Lake Zurich, $\mathbf{L L}=$ Lake Lucerne.

(A)

\begin{tabular}{|c|c|c|c|}
\hline ZOTU\# & Classification & $\begin{array}{l}\text { \# of fauna, where ZOTU enriched, broken down } \\
\text { according to } \mathrm{w}, \mathrm{b} \text {, and } \mathrm{g} \text { (range of } \% \text { fraction of total } \\
\text { reads) }\end{array}$ & $\begin{array}{l}\text { \# of total fauna where } \\
\text { ZOTU highly enriched }\end{array}$ \\
\hline \multicolumn{4}{|c|}{ Fusobacteria } \\
\hline ZOTU389 & Fusobacterium $\mathrm{Cl}$. I & LB: $1 / 11 \mathrm{w}(7 \%)$ & \multirow{4}{*}{$\begin{array}{l}\text { LB: } 5 / 14 \text {; LG: 5/5; LZug: 4/9; } \\
\text { LL: } 1 / 1\end{array}$} \\
\hline ZOTU1 & Fusobacterium $\mathrm{Cl}$. I & $\begin{array}{l}\text { LB: 4/11 w (44-79\%), 1/3 b (87\%), 1/3 g (91\%); LG: 4/5 w } \\
\text { (64-77\%); LZug: 4/7 w (75-97\%) }\end{array}$ & \\
\hline ZOTU7, 22 & Fusobacterium $\mathrm{Cl}$. I & LG: $1 / 1 \mathrm{~b}(62 \%), 1 / 1 \mathrm{~g}(86 \%)$ & \\
\hline ZOTU5, 13 & Fusobacterium $\mathrm{Cl}$. I & LB: $4 / 11 \mathrm{w}(5-24 \%) ; \mathrm{LG}: 1 / 5 \mathrm{w}(65 \%)$ & \\
\hline \multicolumn{4}{|c|}{ Proteobacteria } \\
\hline \multicolumn{4}{|c|}{$\beta$-Proteobacteria } \\
\hline ZOTU6 & $\begin{array}{l}\text { Uncl. Subcl. } \\
\text { (Rhodocyclales) }\end{array}$ & LZ: $1 / 1 \mathrm{w}(59 \%)$ & LZ: $1 / 1$ \\
\hline ZOTU8 & Deefgea (Neisseriales) & LB: $1 / 3 \mathrm{~g}(93 \%)$ & LB: $1 / 14$ \\
\hline \multicolumn{4}{|c|}{$\varepsilon$-Proteobacteria } \\
\hline ZOTU18 & $\begin{array}{l}\text { Wolinella } \\
\text { (Campylobacterales) }\end{array}$ & LZug: $1 / 7$ w $(55 \%)$ & \multirow[t]{2}{*}{ LZug: $2 / 9$} \\
\hline ZOTU9 & Uncl. Cl. & LG: 1/5 w (31\%); LZug: 1/2 b (5-69\%) & \\
\hline \multicolumn{4}{|c|}{$\alpha$-Proteobacteria } \\
\hline ZOTU4 & $\begin{array}{l}\text { Holosporaceae } \\
\text { (Holosporales) }\end{array}$ & LB: 1/11 w (93\%); LZug: 2/7 w (7-60\%) & LB: 1/14; LZug: $1 / 9$ \\
\hline \multicolumn{4}{|c|}{ Bacteroidetes } \\
\hline ZOTU10 & $\begin{array}{l}\text { Flavobacterium } \\
\text { (Flavobacteriales) }\end{array}$ & $\begin{array}{l}\text { LB: } 4 / 11 \mathrm{w}(6-10 \%), 1 / 3 \mathrm{~g}(6 \%) ; \mathrm{LG}: 3 / 5 \mathrm{w}(10-17 \%) \text {; } \\
\text { LZug: } 1 / 7 \mathrm{w}(8 \%)\end{array}$ & - \\
\hline \multicolumn{4}{|c|}{ Parcubacteria } \\
\hline ZOTU199 & Uncl. Cl. I & LB: $2 / 11 \mathrm{w}(7 \%) ; 1 / 3 \mathrm{~b}, 60 \% ; 1 / 3 \mathrm{~g}, 5 \%)$ & LB: $1 / 14$ \\
\hline \multicolumn{3}{|l|}{ TOTAL } & $\begin{array}{l}\text { LB: 8/14; LG: 5/5; LZug: } \\
\text { 7/9; LZ: 1/1; LL: } 1 / 1\end{array}$ \\
\hline
\end{tabular}


(B)

\begin{tabular}{|c|c|c|c|}
\hline ZOTU\# & Classification & $\begin{array}{l}\text { \# of fauna, where ZOTU enriched, broken down } \\
\text { according to } w, b \text {, and } g \text { (range of \% fraction of } \\
\text { total reads) }\end{array}$ & $\begin{array}{l}\text { \# of total fauna where } \\
\text { ZOTU highly enriched }\end{array}$ \\
\hline \multicolumn{4}{|c|}{ Fusobacteria } \\
\hline ZOTU1 & Fusobacterium $\mathrm{Cl}$. I & $L Z(1 / 1 b)(8 \%)$ & \multirow{2}{*}{$\begin{array}{l}L Z(3 / 7>5 \% ; 1 / 7 \\
>50 \%)\end{array}$} \\
\hline ZOTU5, 13 & Fusobacterium $\mathrm{Cl}$. I & $L Z(2 / 6 w)(6-57 \%)$ & \\
\hline \multicolumn{4}{|c|}{ Proteobacteria } \\
\hline \multicolumn{4}{|c|}{$\gamma$-Proteobacteria } \\
\hline ZOTU11 & Serratia (Enteromonadales) & $L L(1 / 6 b)(83 \%)$ & \multirow{3}{*}{$\begin{array}{l}L L(5 / 10>5 \% ; 4 / 10 \\
>50 \%)\end{array}$} \\
\hline ZOTU21, 3 & Aeromonas (Aeromonadales) & $L L(1 / 4 w, 79 \% ; 2 / 6 b, 11-78 \% ; 2 / 6 g, 98-99 \%)$ & \\
\hline ZOTU26 & Uncl. Cl. (Pseudomonadales) & $\operatorname{LL}(1 / 4 w)(40 \%)$ & \\
\hline \multicolumn{4}{|c|}{$\beta$-Proteobacteria } \\
\hline ZOTU6 & Uncl. Subcl. (Rhodocyclales) & $L L(1 / 4 w)(56 \%)$ & \multirow{2}{*}{$\begin{array}{l}L L(3 / 10>5 \% ; 2 / 10 \\
>50 \%)\end{array}$} \\
\hline ZOTU12 & Uncl. Subcl. (Burkholderiales) & $L L(2 / 6 b)(22-56 \%)$ & \\
\hline \multicolumn{4}{|c|}{$\alpha$-Proteobacteria } \\
\hline ZOTU2 & Wolbachia (Rickettsiales) & $L Z(2 / 6 w), L L(1 / 4 w, 3 / 6 b)(42-71 \%)$ & $\begin{array}{l}L Z(2 / 7>5 \% ; 2 / 7 \\
>50 \%) ; L L(5 / 10>5 \% \\
4 / 10>50 \%)\end{array}$ \\
\hline \multicolumn{4}{|c|}{ Bacteroidetes } \\
\hline ZOTU28 & $\begin{array}{l}\text { Uncl. Wastewater \& Gut Group } \\
\text { (Bacteroidales) }\end{array}$ & $L Z(1 / 6 w)(72 \%)$ & $L Z(1 / 7>50 \%)$ \\
\hline \multicolumn{4}{|l|}{ Firmicutes } \\
\hline ZOTU19 & "Insect Gut Cl." (Clostridiales) & $\operatorname{LL}(1 / 4 w, 2 / 6 g)(19-31 \%)$ & $\begin{array}{l}L L(3 / 10>5 \% ; 0 / 10 \\
>50 \%)\end{array}$ \\
\hline \multicolumn{3}{|l|}{ TOTAL } & $\begin{array}{l}\text { LB: 0/2; LZ: 3/7; LL: } \\
9 / 10\end{array}$ \\
\hline
\end{tabular}




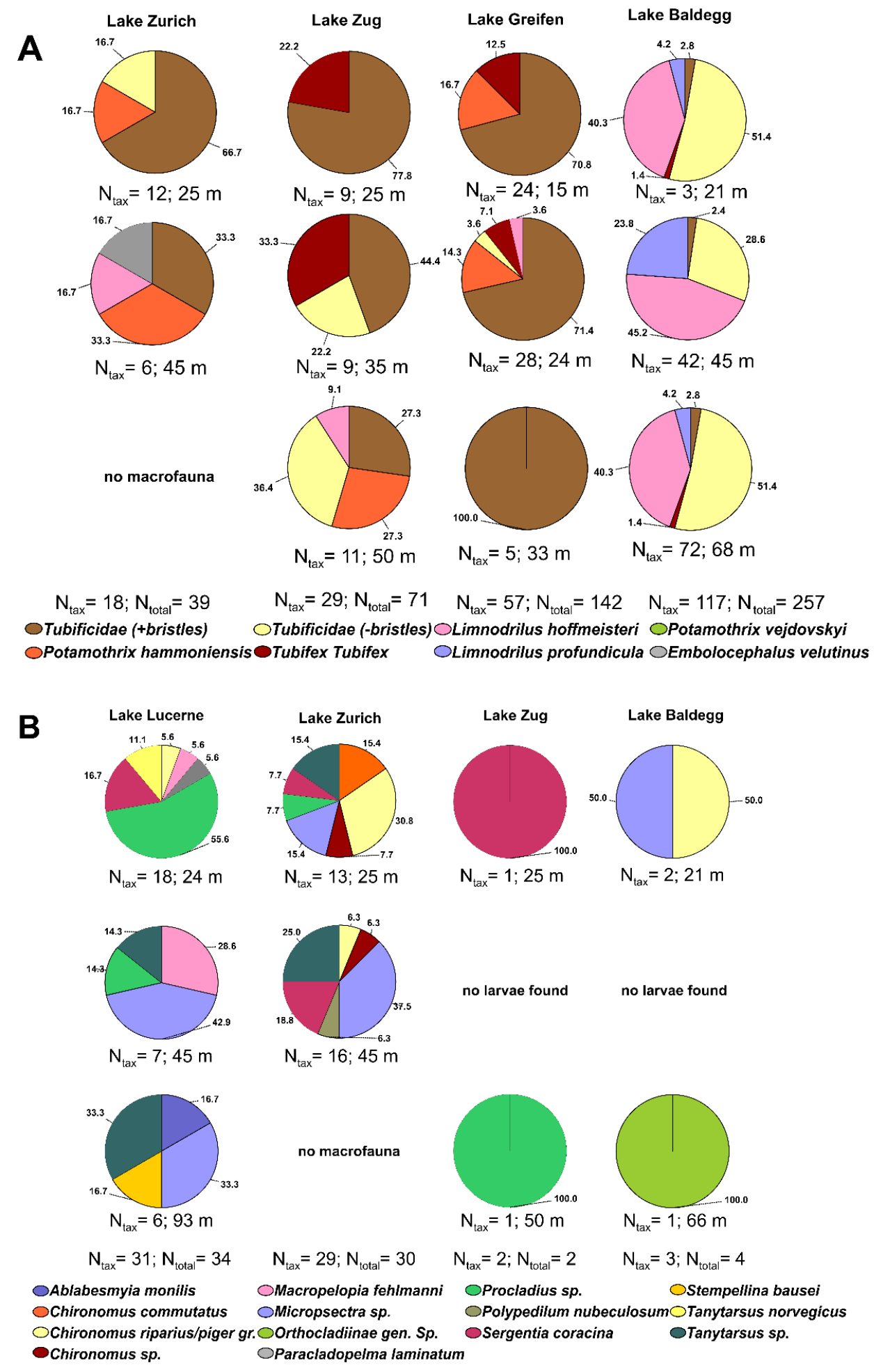

5 Figure S1: Taxonomy results for selected individuals of the two main classes found (A: oligochaete worms, Ntax=222, Ntot = 513; B: chironomid larvae, $\mathrm{Ntax}=65, \mathrm{Ntot}=\mathbf{7 0}$ ) for each lake and station individually. Numbers indicate the $\%$ abundance of taxonomically analyzed individuals. No chironomid larvae were found in Lake Greifen and at station 2 of Lake Baldegg (45 m) and Lake Zug (35 m). In Lake Lucerne only 4 oligochaetic worms were found of which 1 was taxonomically analyzed (Potamothrix vejdoyski).No Macrofauna was found at the deep station of Lake Zurich (137 m). 


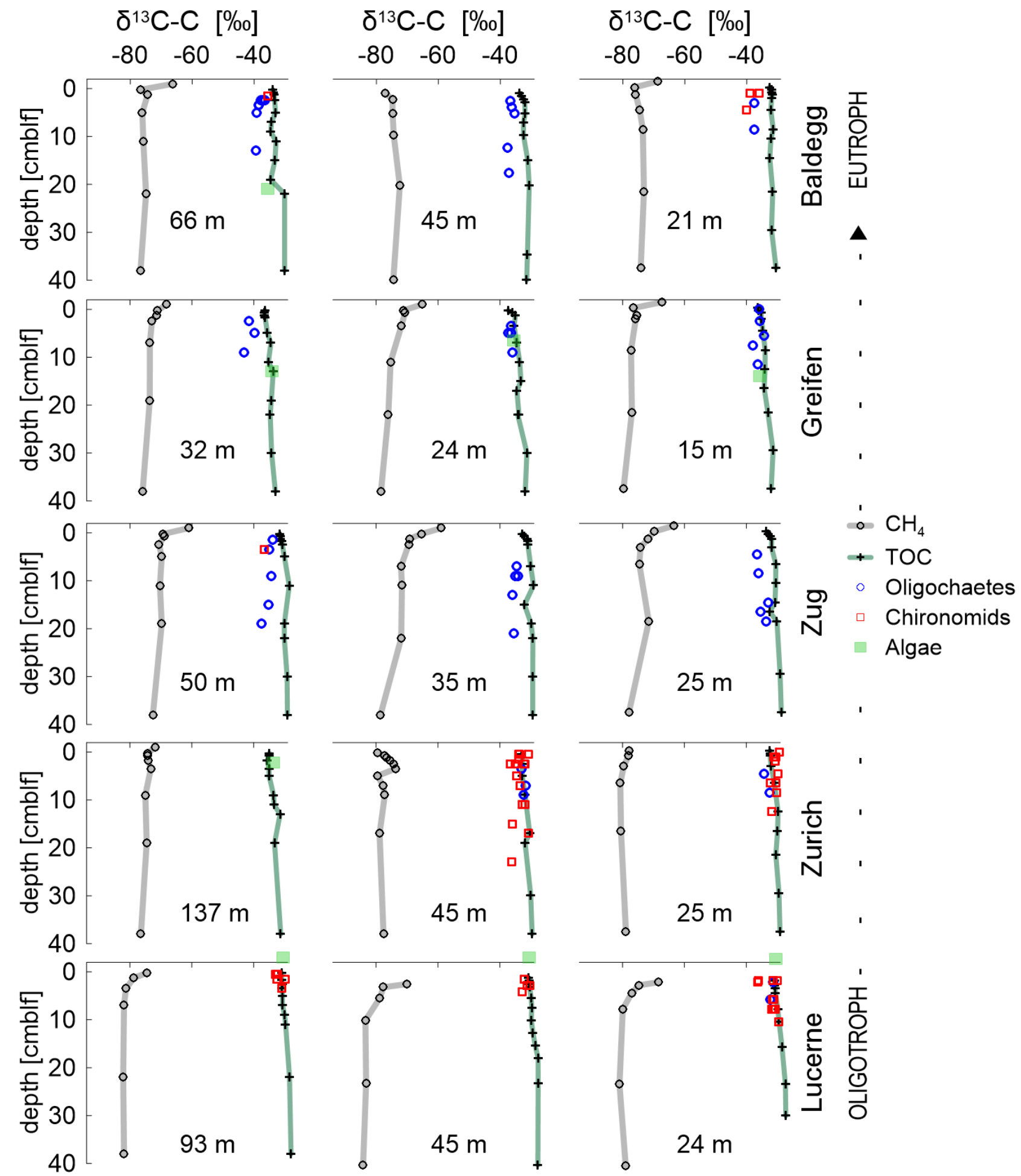

Figure S2: $\delta^{13} \mathrm{C}$ of TOC, methane, specific sediment layers (water column phytoplankton and algal bloom sediment layers), oligochaetes and chironomid larvae vs. sediment depth (cmblf). 
Sediment

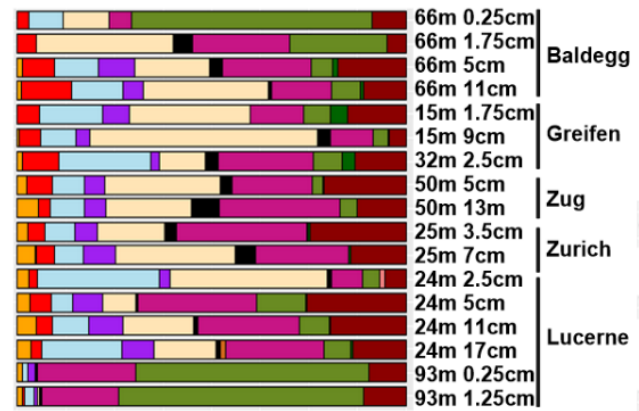

Tubes

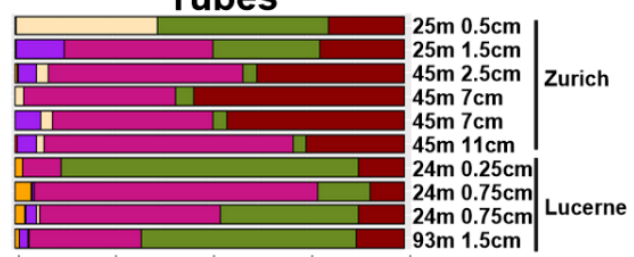

$\begin{array}{lllll}0 & 25 & 50 & 75 & 100\end{array}$

Relative abundance

( $\%$ of total sequences)

\section{Archaea Phylum}

Aenigmarchaeota

Aigarchaeota

Altiarchaeales

Bathyarchaeota

Diapherotrites

Euryarchaeota

Lokiarchaeota

Odinarchaeota

Pacearchaeota

Thaumarchaeota

Thorarchaeota

Unclassified.Asgardarchaeota.cluster

Woesearchaeota

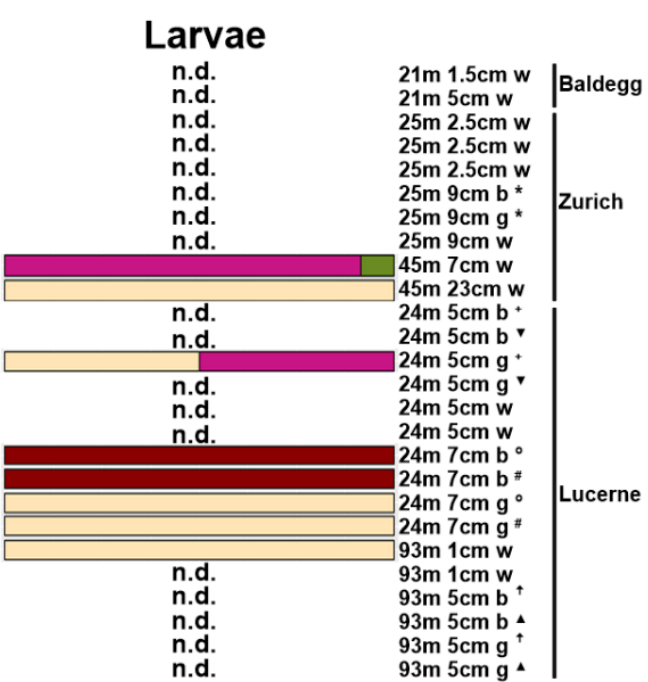

Oligochaetes

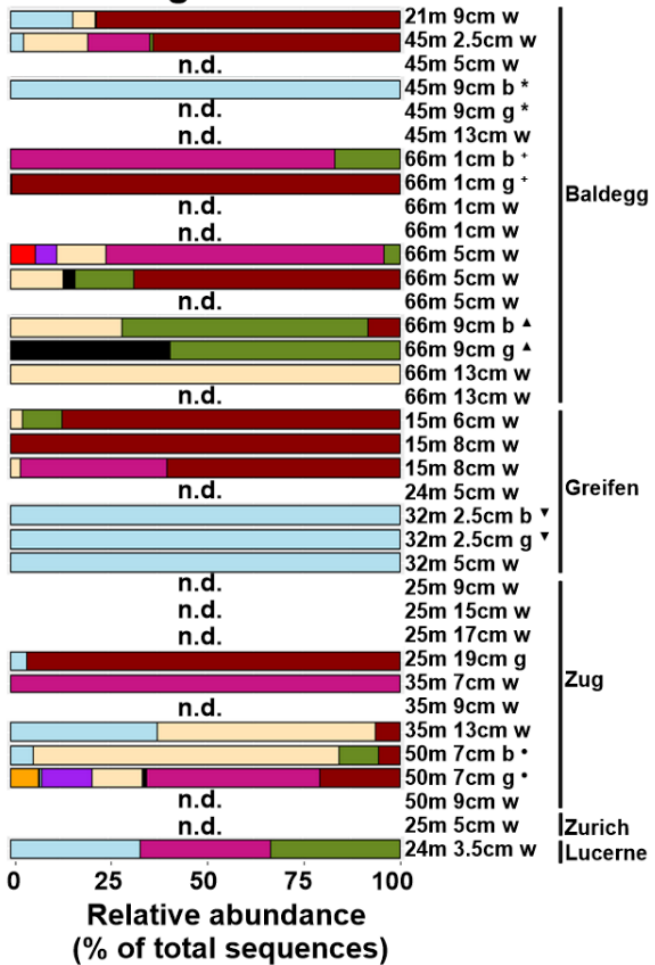

Figure S3: relative abundance of archaeal sequences (phylum level) for sediment, tubes, chironomid larvae and oligochaete samples. 


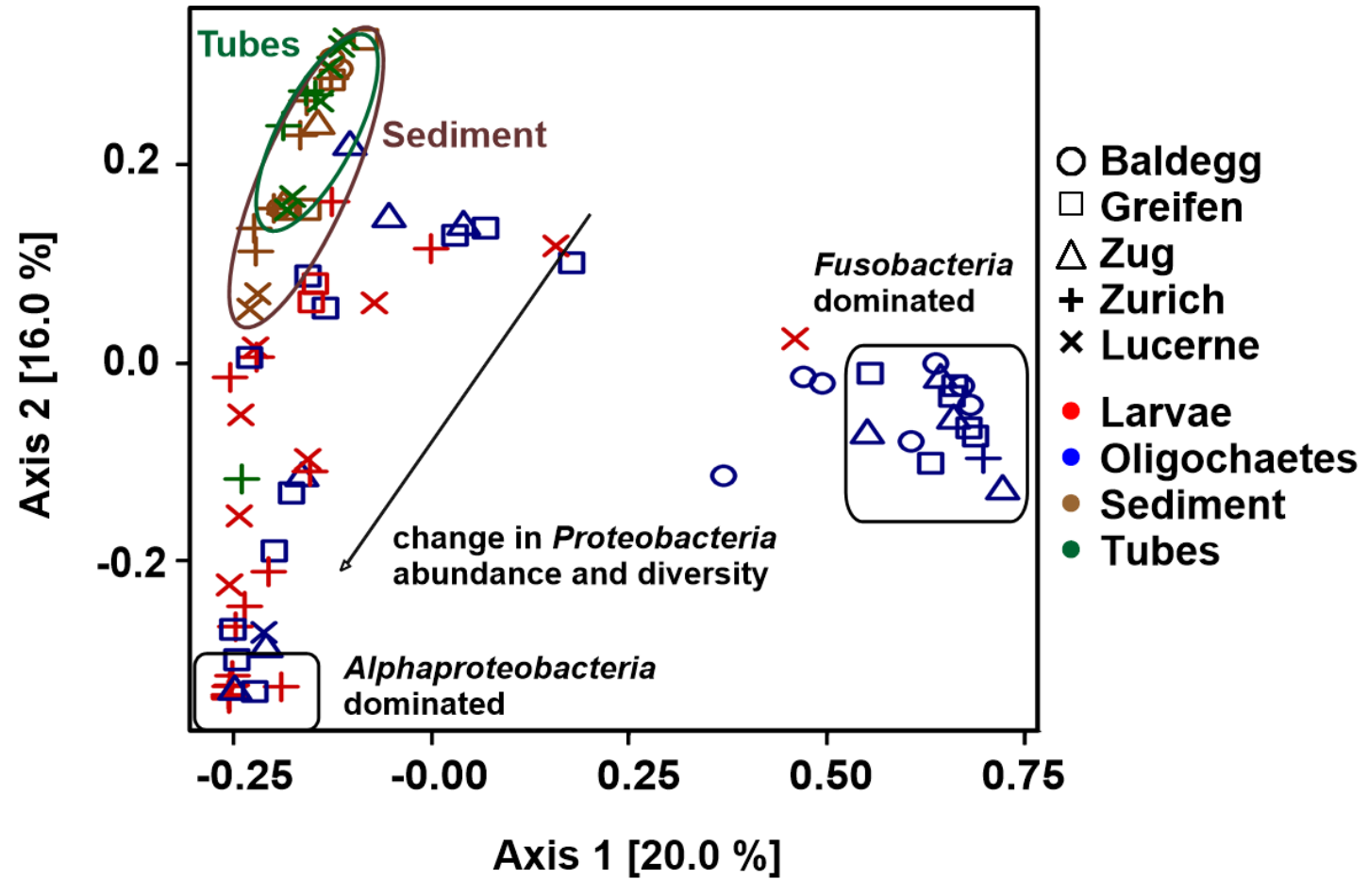

Class

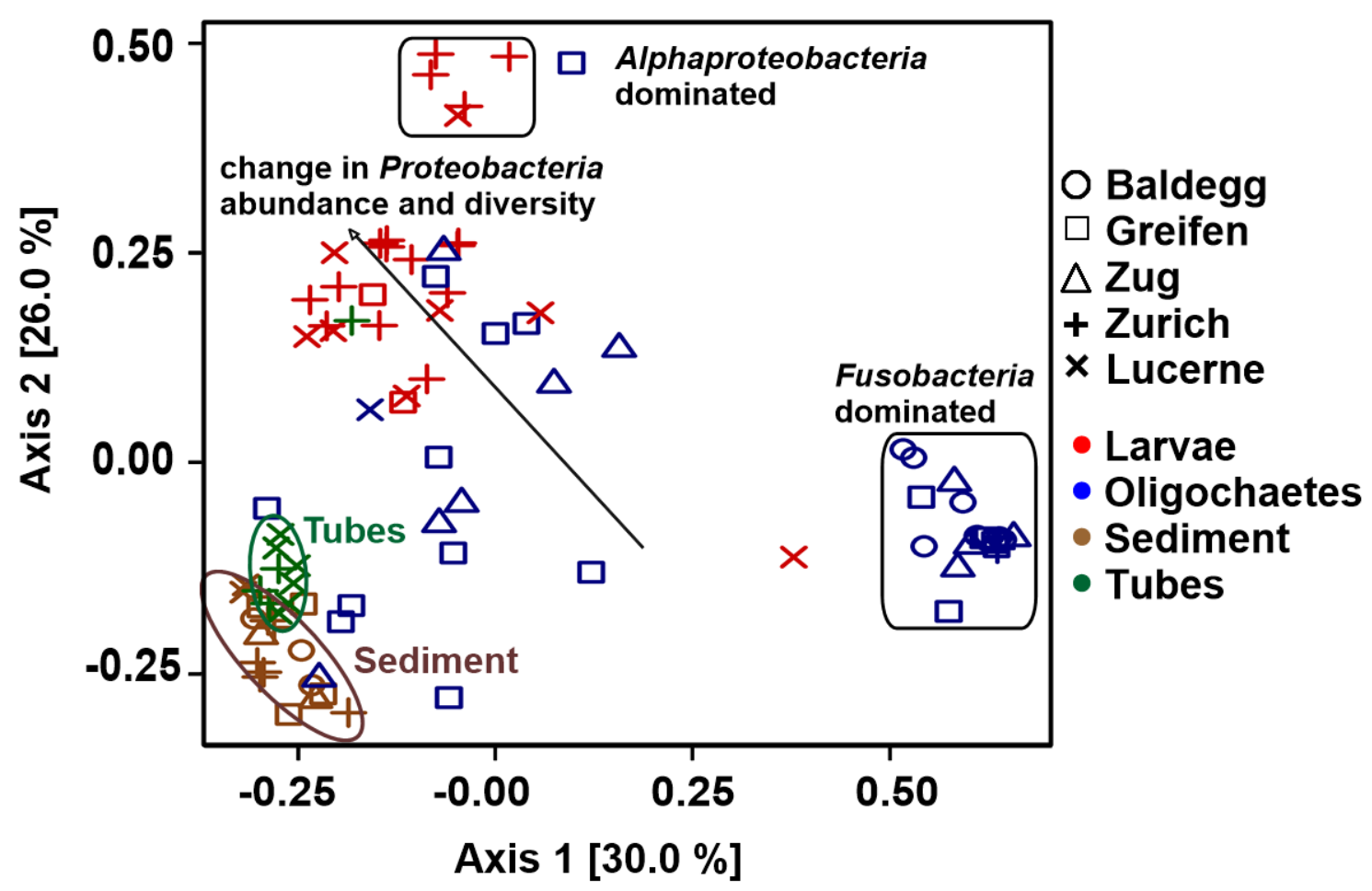




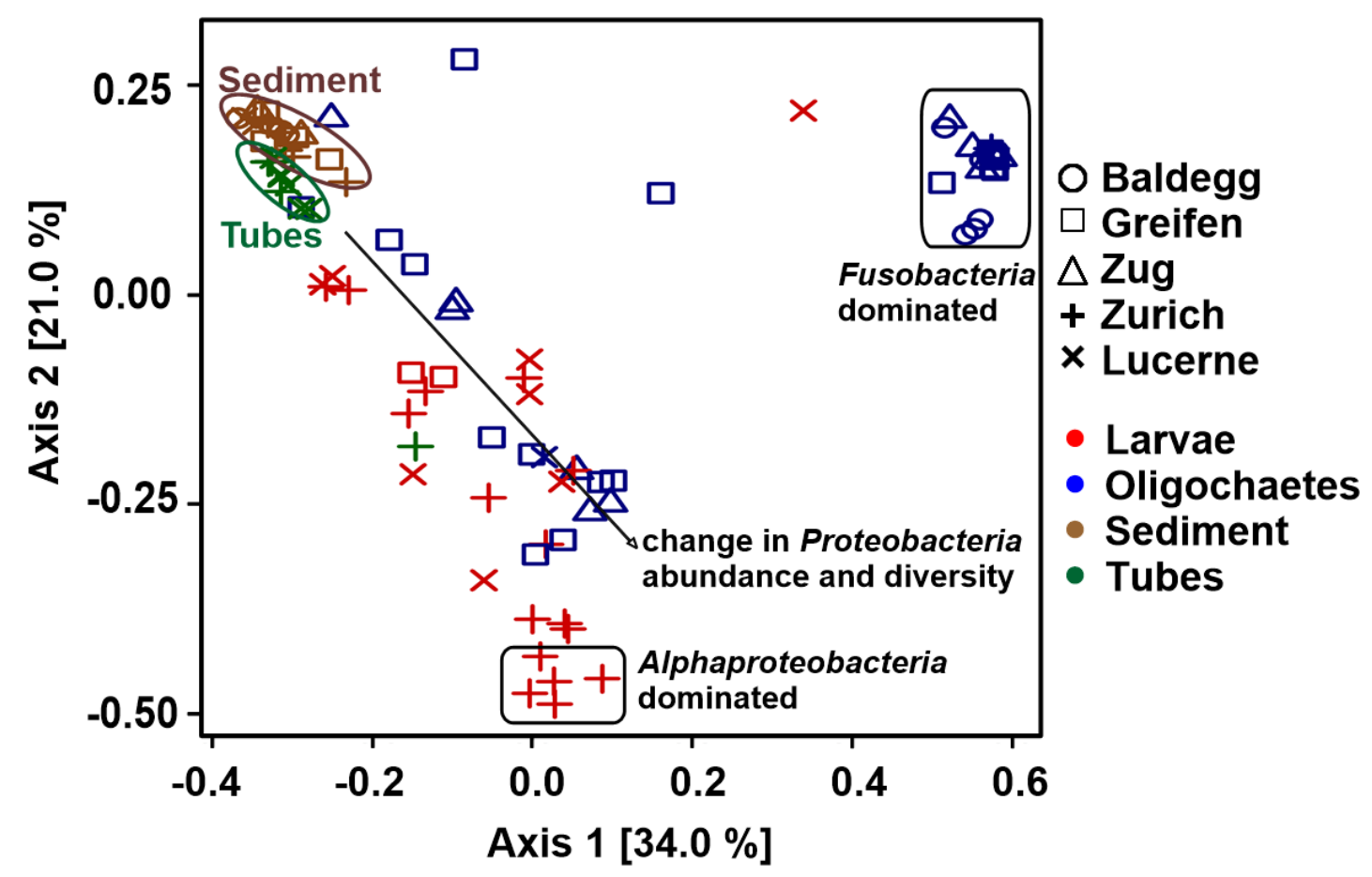

Genus

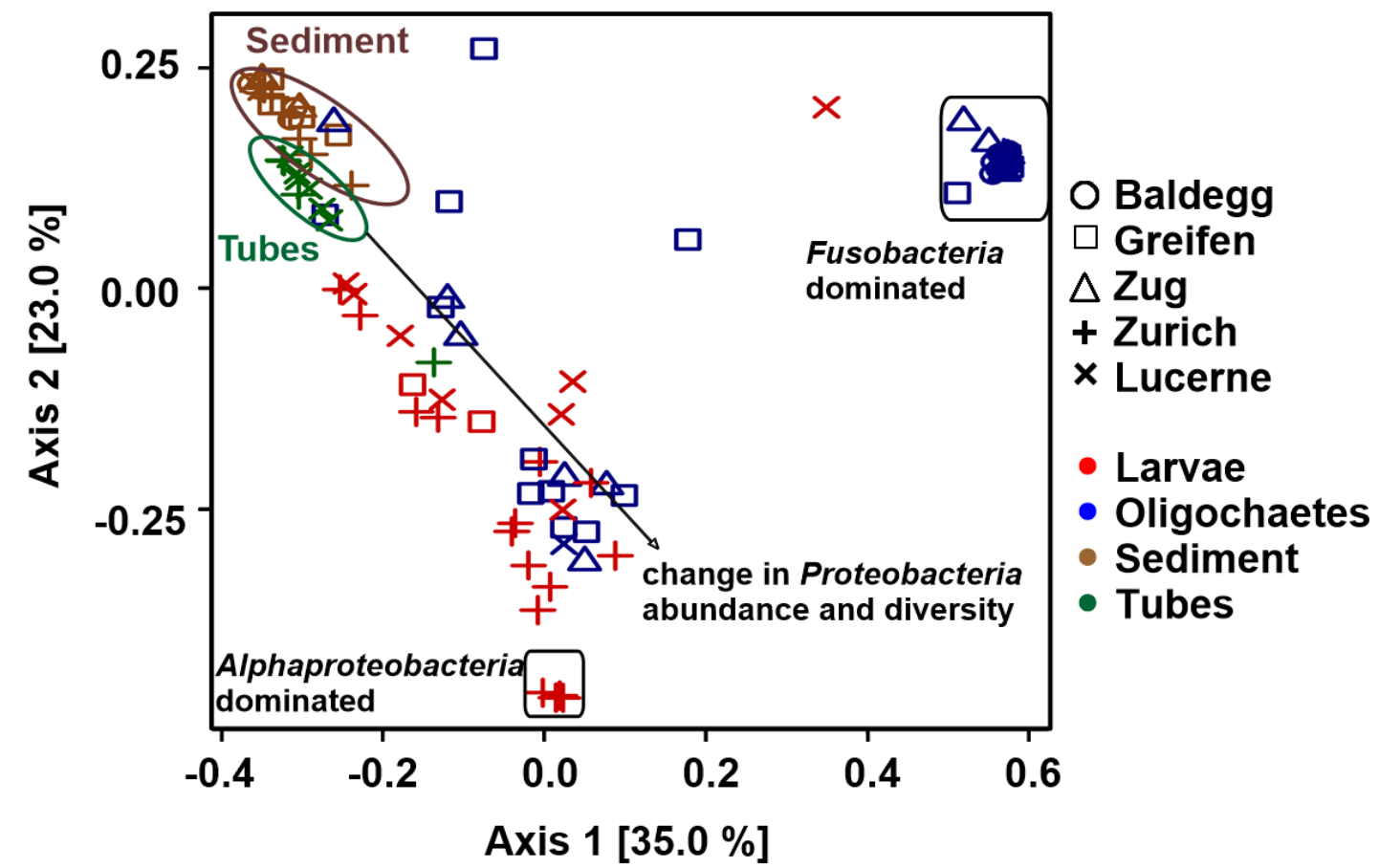

Figure S4: PCoA analysis of the relative abundance of Bacteria on the phylum, class, family and genus level. Distances are calculated using Bray Curtis distances. 
TOC [\%] $\quad \delta^{13} \mathrm{C}-\mathrm{TOC}[\%] \quad$ Chla $[\mu \mathrm{g} / \mathrm{g} \mathrm{sedww]}$

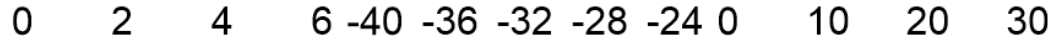

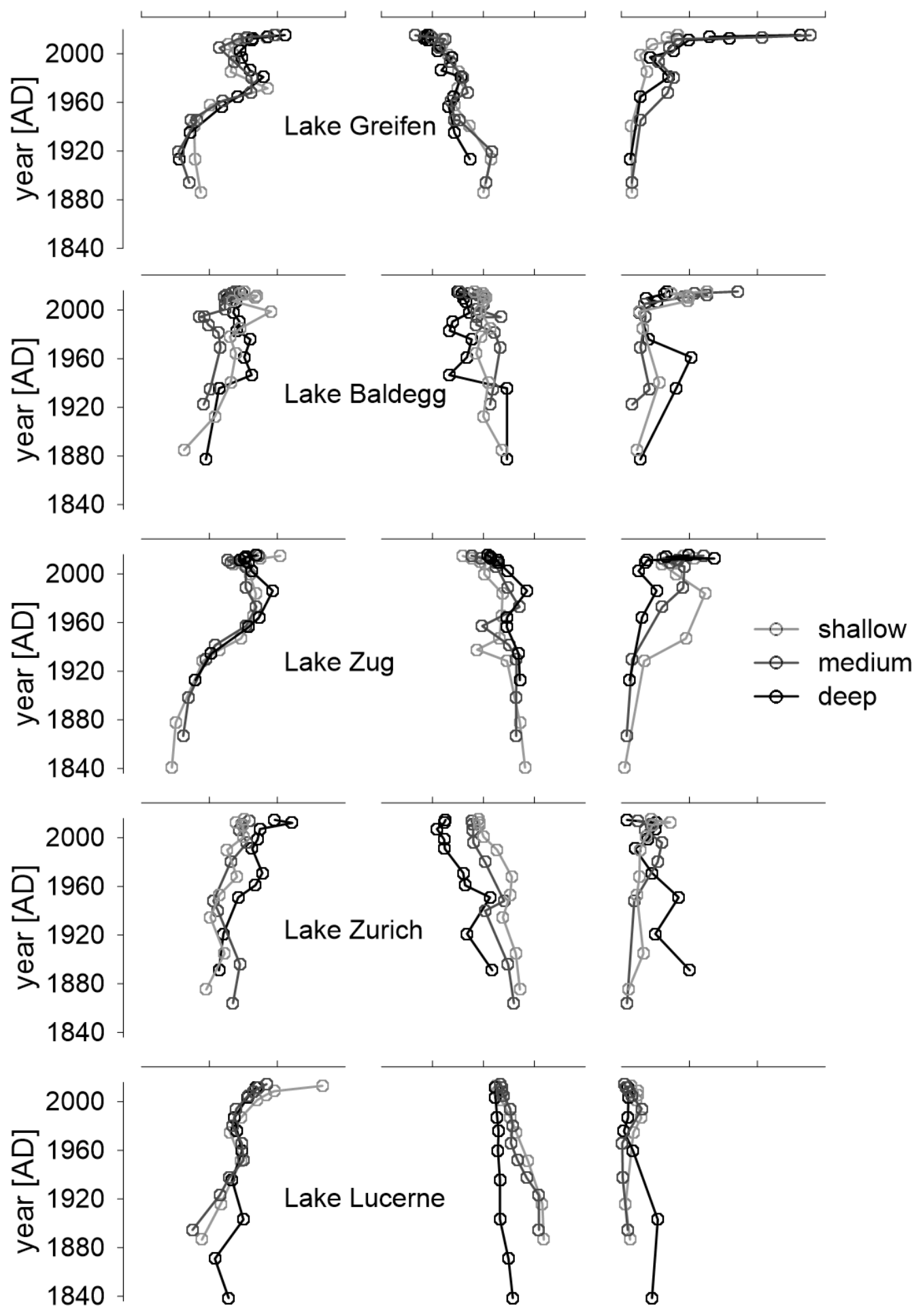

Figure S5: Total organic carbon (TOC) in [\%], stable carbon isotopes of TOC $\left(\delta^{13} \mathrm{C}-\mathrm{TOC}\right)$ in $[\%$ ] and Chla concentrations $[\mu \mathrm{g} / \mathrm{g}$ sedww] for each lake vs sediment age [AD]. Three stations per lake are plotted in one subplot. Light grey, open triangles= shallowest station, dark grey, closed circles $=$ medium station, black, open circles = bottom station. 


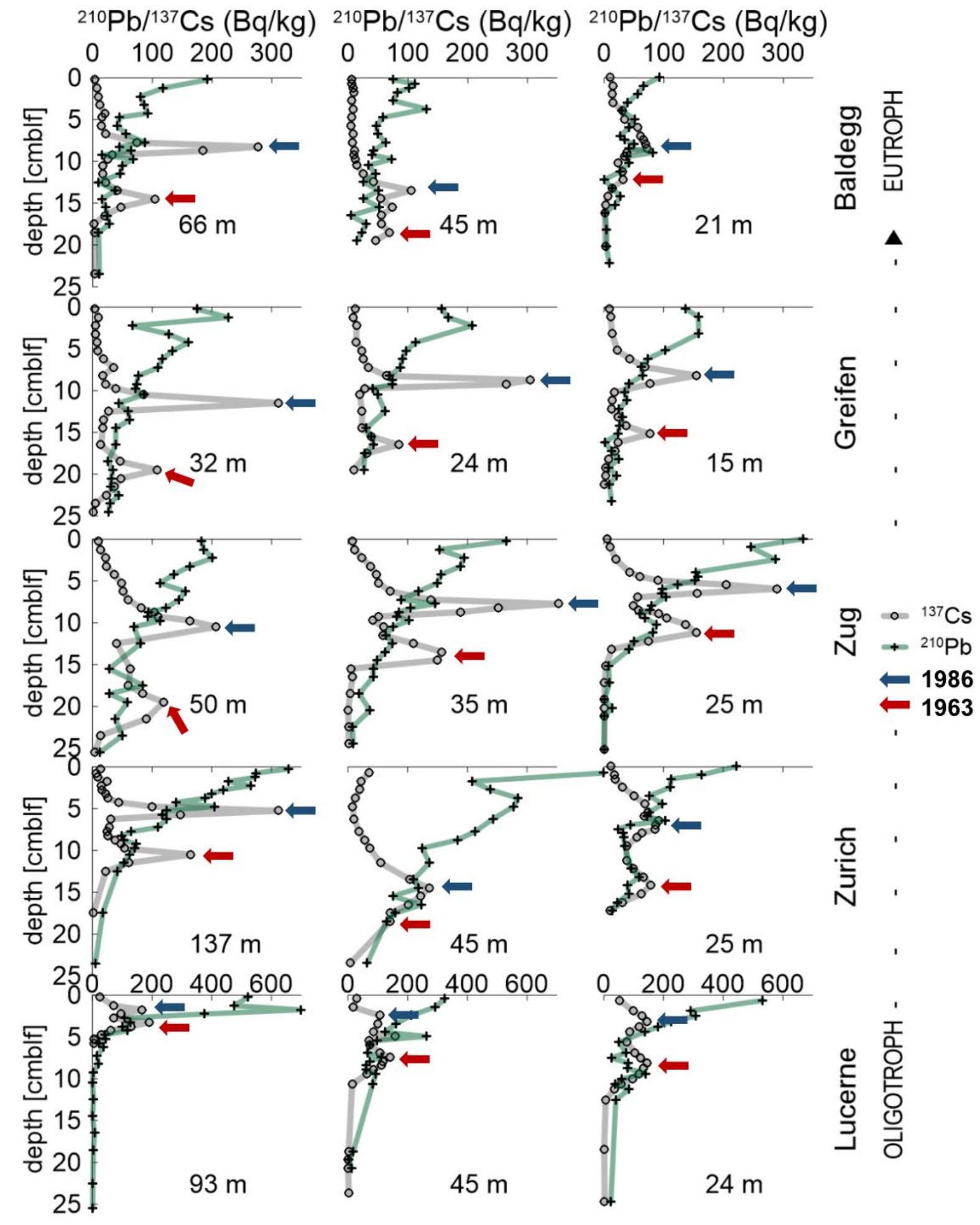

Figure S6: Profile of ${ }^{210} \mathrm{~Pb}$ unsupported and ${ }^{137} \mathrm{Cs}$ in $\mathrm{Bq} / \mathrm{kg}$, along sediment depth in centimetre below lake floor (cmblf) for each station. Blue arrow indicates the $137 \mathrm{Cs}$ peak due to the Chernobyl accident in 1986 and the red arrow indicates bomb testing in 1963. Please note different $x$-axes for Lake Lucerne. 
(A)

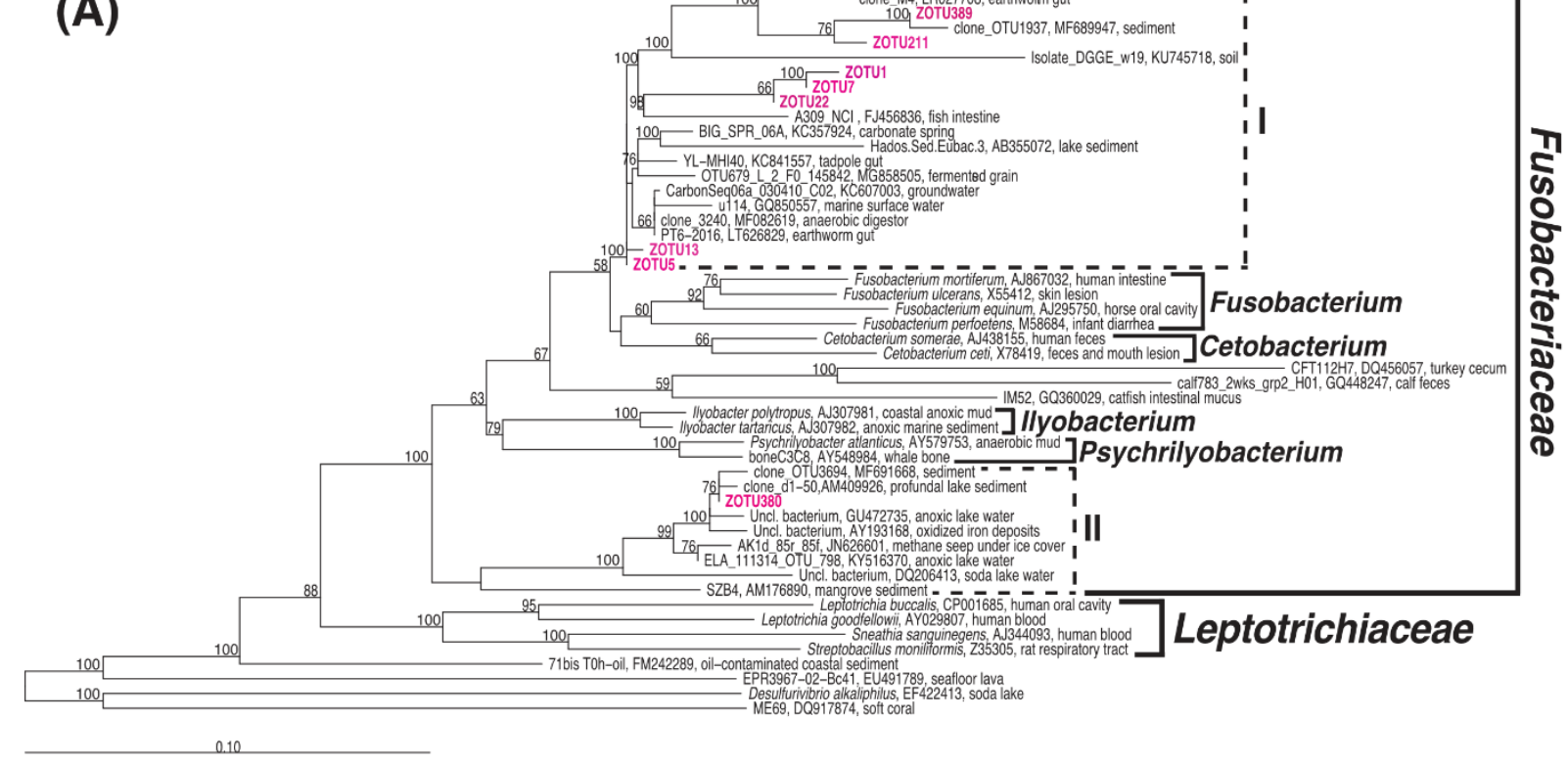


(B)

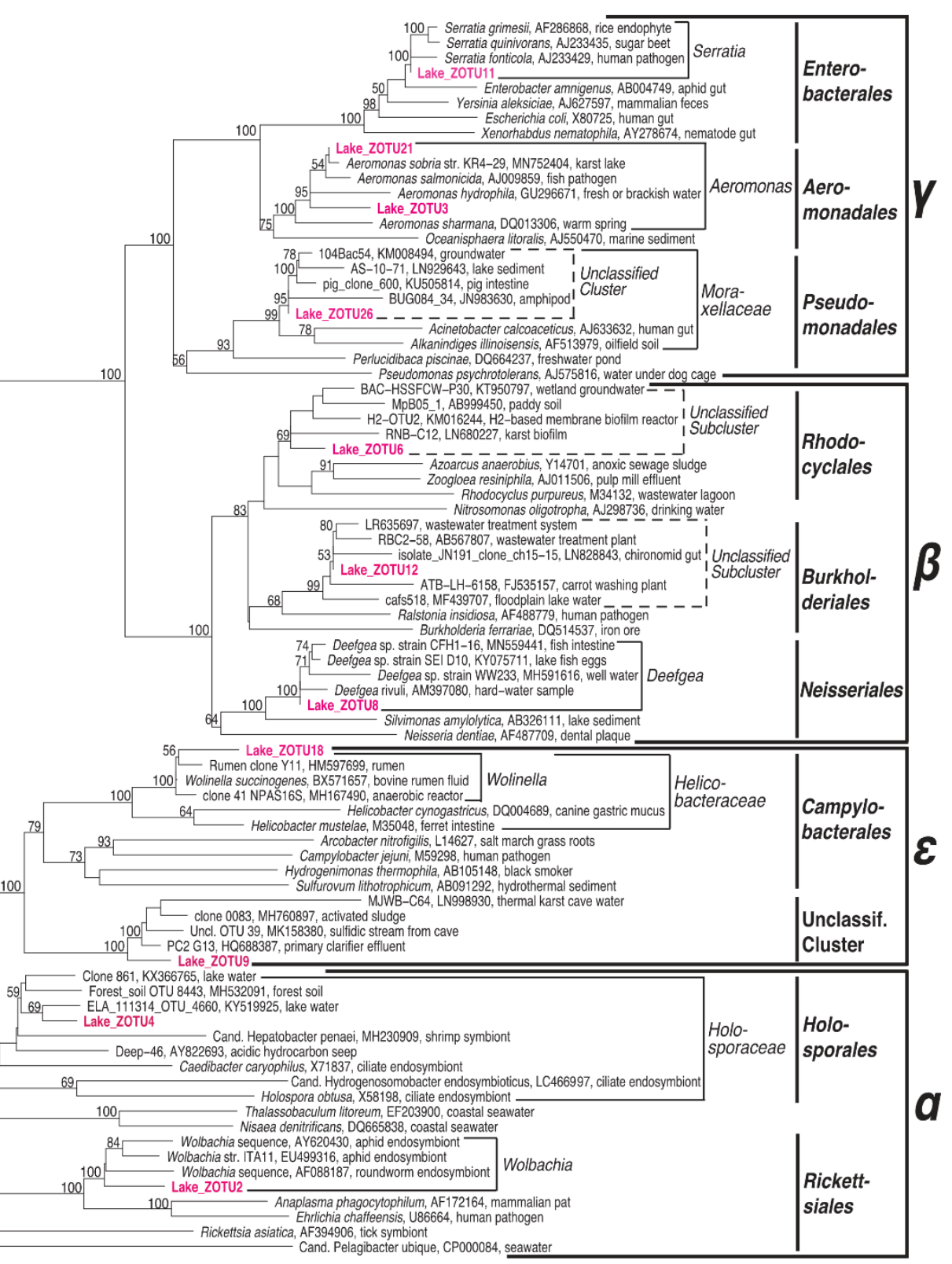

010 

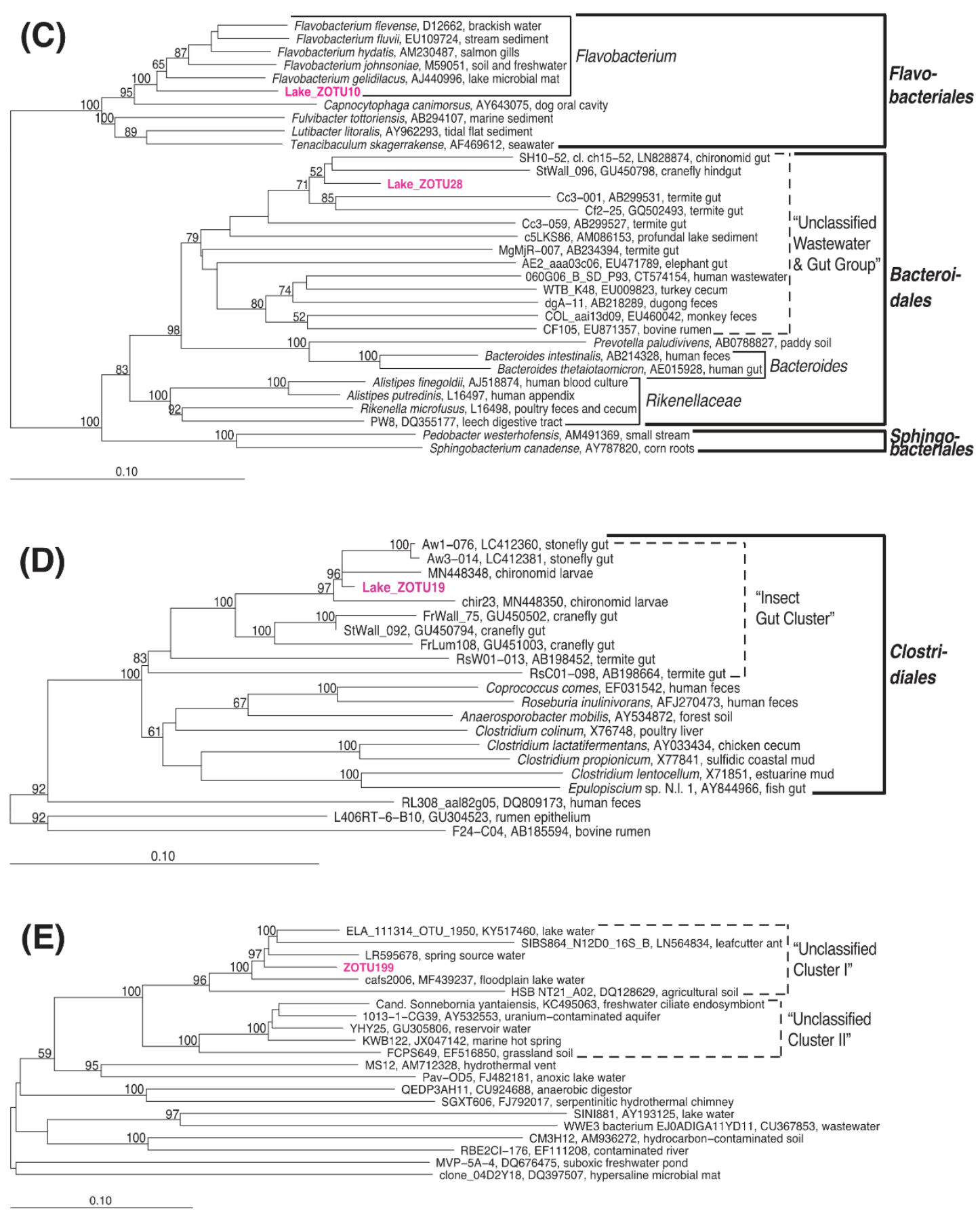

Figure S7: Phylogenetic assignment for sequences of Fusobacteria (A), Proteobacteria (B), Bacteroidetes (C), Firmicutes (D) and Parcubacteria (E) performed in ARB (please see SI Table S8). The trees show IDs and source environments of the closest related environmental DNA sequences in black, the sequences detected in this study are marked in magenta.

\section{$5 \quad$ References}

Bernasconi, S. M., Barbieri, A., and Simona, M.: Carbon and nitrogen isotope variations in sedimenting organic matter in Lake Lugano, Limnol Oceanogr, 42, 1755-1765, 1997.

Boon, P. I. and Bunn, S. E.: Variations in the Stable-Isotope Composition of Aquatic Plants and Their Implications for FoodWeb Analysis, Aquat Bot, 48, 99-108, 1994.

10 Brinkhurst, R. O.: British and other marine and estuarine oligochaetes, British and other marine and estuarine oligochaetes., 1982. 1982.

Brinkhurst, R. O. and Chua, K. E.: Preliminary investigation of the exploitation of some potential nutritional resources by three sympatric tubificid oligochaetes, Journal of the Fisheries Board of Canada, 26, 2659-2668, 1969.

Brodersen, K. P., Pedersen, O., Lindegaard, C., and Hamburger, K.: Chironomids (Diptera) and oxy - regulatory capacity: an experimental approach to paleolimnological interpretation, Limnol Oceanogr, 49, 1549-1559, 2004. 
Chaloner, D. T. and Wotton, R. S.: Tube building by larvae of 3 species of midge (Diptera: Chironomidae), J N Am Benthol Soc, 15, 300-307, 1996.

Cloern, J. E., Canuel, E. A., and Harris, D.: Stable carbon and nitrogen isotope composition of aquatic and terrestrial plants of the San Francisco Bay estuarine system, Limnol Oceanogr, 47, 713-729, 2002.

5 Goedkoop, W., ÅKerblom, N., and Demandt, M. H.: Trophic fractionation of carbon and nitrogen stable isotopes in Chironomus riparius reared on food of aquatic and terrestrial origin, Freshwater Biol, 51, 878-886, 2006.

Hollander, D. J., Mckenzie, J. A., Hsu, K. J., and Huc, A. Y.: Application of an Eutrophic Lake Model to the Origin of Ancient Organic-Carbon-Rich Sediments, Global Biogeochem Cy, 7, 157-179, 1993.

Lazerte, B. D.: Stable Carbon Isotope Ratios - Implications for the Source of Sediment Carbon and for Phytoplankton Carbon Assimilation in Lake Memphremagog, Quebec, Can J Fish Aquat Sci, 40, 1658-1666, 1983.

Lehmann, M. F., Bernasconi, S. M., McKenzie, J. A., Barbieri, A., Simona, M., and Veronesi, M.: Seasonal variation of the delta C-13 and delta N-15 of particulate and dissolved carbon and nitrogen in Lake Lugano: Constraints on biogeochemical cycling in a eutrophic lake, Limnol Oceanogr, 49, 415-429, 2004.

Ludwig, W., Strunk, O., Westram, R., Richter, L., Meier, H., Yadhukumar, Buchner, A., Lai, T., Steppi, S., Jobb, G., Forster,

15 W., Brettske, I., Gerber, S., Ginhart, A. W., Gross, O., Grumann, S., Hermann, S., Jost, R., Konig, A., Liss, T., Lussmann, R., May, M., Nonhoff, B., Reichel, B., Strehlow, R., Stamatakis, A., Stuckmann, N., Vilbig, A., Lenke, M., Ludwig, T., Bode, A., and Schleifer, K. H.: ARB: a software environment for sequence data, Nucleic Acids Res, 32, 1363-1371, 2004.

Martin, P., Martinez-Ansemil, E., Pinder, A., Timm, T., and Wetzel, M. J.: Global diversity of oligochaetous clitellates ("Oligochaeta"; Clitellata) in freshwater, Hydrobiologia, 595, 117-127, 2008.

20 Moog, O.: Fauna Aquatica Austriaca, Edition 2002, Wassserwirtschaftskataster, Bundesministerium für Land und Forstwirtschaft, Umwelt und Wasserwirtschaft, Vienna, 2002. 2002.

Moore, J. W.: Factors influencing algal consumption and feeding rate in Heterotrissocladius changi Saether and Polypedilum nebeculosum (Meigen)(Chironomidae: Diptera), Oecologia, 40, 219-227, 1979.

Pillot, H. K. M.: Chironomidae Larvae, Vol. 2: Chironomini: Biology and Ecology of the Chironomini, Brill, 2009.

25 Saether, O. A.: The influence of eutrophication on deep lake benthic invertebrate communities. In: Eutrophication of Deep Lakes, Elsevier, 1980.

Stevenson, R. J., Bothwell, M. L., Lowe, R. L., and Thorp, J. H.: Algal ecology: Freshwater benthic ecosystem, Academic press, 1996.

Stief, P., Nazarova, L., and de Beer, D.: Chimney construction by Chironomus riparius larvae in response to hypoxia: microbial implications for freshwater sediments, J N Am Benthol Soc, 24, 858-871, 2005.

Vallenduuk, H. J. and Pillot, H. K. M.: Chironomidae Larvae, Vol. 1: Tanypodinae: General Ecology and Tanypodinae, Brill, 2007.

Van Haaren, T. and Soors, J.: Aquatic Oligochaeta of the Netherlands and Belgium: Identification Key to the Oligochaetes, BRILL, 2013.

35 Vuorio, K., Meili, M., and Sarvala, J.: Taxon-specific variation in the stable isotopic signatures (delta C-13 and delta N-15) of lake phytoplankton, Freshwater Biol, 51, 807-822, 2006. 